\title{
Towards head and neck cancer prevention in Nigeria: Insights from the CHANCE Programme
}

\author{
Kehinde K. Kanmodi ${ }^{1}$, Omotayo F. Fagbule ${ }^{1}$
}

AFFILIATION

1 Campaign for Head and Neck Cancer Education (CHANCE) Program, Cephas Health Research Initiative Inc, Ibadan, Nigeria

CORRESPONDENCE TO

Kehinde K. Kanmodi. Campaign for Head and Neck Cancer Education (CHANCE) Program, Cephas Health Research Initiative Inc, Ibadan, Nigeria. E-mail: kanmodikehinde@yahoo.com
KEYWORDS

prevention, public health, community-based intervention, head and neck cancer

Received: 23 April 2020, Revised: 1 May 2020

Accepted: 14 May 2020

https://doi.org/10.18332/popmed/122454

Popul. Med. 2020;2(June):16

\section{Dear Editor,}

Head and neck cancer (HNC) is a leading cause of cancerrelated deaths, globally. Every year, about 55000 new cases and 300000 deaths of HNC, are reported globally ${ }^{1}$. Similarly, the burden of HNC in Nigeria is also enormous, being a leading cause of cancer-related deaths among Nigerians ${ }^{2}$. In order to combat the enormous burden of HNC in Nigeria, through primary prevention of the disease, an intervention programme named 'Campaign for Head and Neck Cancer Education (CHANCE) Programme' was established in 2016 by a group of dentists in Nigeria ${ }^{3}$. Through this programme, multiple research projects and piloted public health education programmes on HNC have been conducted ${ }^{4-9}$.

The primary rationales for launching the CHANCE Programme were to address: 1) the high prevalence rates of the HNC major risk factors (oral sex, tobacco use, and alcohol drinking) among Nigerian youth ${ }^{7} ; 2$ ) the huge burden of HNC disease in Nigeria ${ }^{2}$; and 3) the dearth of scientific literature on public health aspects of HNC disease in Nigeria.

So far, the CHANCE Programme has been run for 3 years and some months, and some specific lessons of public health relevance have been learnt from the programme $e^{1,4-9}$. We were able to identify that: 1 ) many Nigerians are not aware of HNC disease ${ }^{4-8}$; 2) many Nigerians that claimed to be aware of HNC disease actually lacked adequate knowledge about its risk factors, symptoms, and treatment ${ }^{4-7}$; 3) many Nigerians are willing to know more about HNC disease ${ }^{4,5,7} ; 4$ ) school-based HNC programmes are well accepted by youth in the school communities ${ }^{5,7}$; 5) Nigerian in-school youth are willing to voluntarily play the role of HNC prevention advocates by teaching others about $\mathrm{HNC}^{5,7}$; and 6) schoolbased HNC education programmes can be implemented at minimal financial cost through planned involvement of inschool adolescents as HNC prevention advocates ${ }^{5,7}$.

The above factors are good social indicators showing that many Nigerian school communities are willing to get engaged in HNC prevention programmes; and through this engagement, much can be achieved in regard to HNC prevention in Nigeria.

Based on the above, it is highly recommended that the Nigeria government at all levels (federal, state, and local) should formulate and implement policies that will drive the establishment of oral health promotion programmes in Nigeria secondary schools. Through these, massive schoolbased HNC education interventions can be successfully implemented.

\section{REFERENCES}

1. Shaw R, Beasley N. Aetiology and risk factors for head and neck cancer: United Kingdom National Multidisciplinary Guidelines. J Laryngol Otol. 2016;130(Suppl 2):S9-S12. doi:10.1017/s0022215116000360

2. da Lilly-Tariah OB, Somefun AO, Adeyemo WL. Current evidence on the burden of head and neck cancers in Nigeria. Head Neck Oncol. 2009;1(1):14. doi:10.1186/1758-3284-1-14

3. About the Cephas Health Research Initiative, Inc. in Nigeria. In Kanmodi KK, Merrick J(Eds). The traditional Sakkiya practice: A public health issue in Northern Nigeria. New York, NY: Nova Science; 2019;147-148.

4. Kanmodi KK, Nnebedum N, Bello M, Adesina M, Fagbule OF, Adesoye O. Head and neck cancer awareness: a survey of young people in international communities. Int J Adolesc Med Health. 2019. doi:10.1515/ijamh-2018-0231

5. Kanmodi KK, Fagbule OF. Does head and neck cancer (HNC) education have impact on adolescents' knowledge and attitude towards HNC and HNC peer education? An example from Nigeria. Int J Child Adolesc Health. 2018;11(3):343-347.

6. Kanmodi KK, Fagbule OF, Aladelusi TO. Prevalence of shisha (waterpipe) smoking and awareness of head and neck cancer among Nigerian secondary school students: a preliminary survey. Int Public Health J. 2018;10(2):210-214.

7. Kanmodi KK, Osunro KS, Nwafor NJ, Kanmodi PA. Impact of 
head and neck cancer (HNC) education on HNC knowledge and attitudes toward HNC peer and non-peer education: A school-based pilot study. Yen Med J. 2020;2(2):47-55.

8. Kanmodi KK, Chidiebere O, Nwafor NJ, Amoo BA. Knowledge of HPV, HPV-induced cancers, and HPV vaccine among university students in medical laboratory science disciplines: Nigerian study. J Obstet Gynecol Investig 2020;3(1):e1-e7. doi:10.5114/jogi.2020.94420

9. Nwafor NJ, Kanmodi KK, Omoleke SA, Enaibe TW. Knowledge of shisha and attitudes toward clinical counseling of shisha smokers amongst doctors: Nigerian study. Med J Zambia. 2020;47(1):16-24. 